\title{
Mikulicz's Disease With Immune Thrombocytopenia: A New Immunoglobulin G4-Mediated Disorder and Literature Review
}

\author{
Shu LI@, Cong DENG@, Jinwei CHEN@, Fen LI@ \\ Department of Rheumatology and Immunology, The Second Xiangya Hospital, Central South University, Changsha, China
}

\begin{abstract}
Mikulicz's disease (MD), an immunoglobulin G4 (IgG4)-related disease, is a fibrosis-associated inflammatory disease characterized by painless bilateral swelling of lacrimal and salivary glands. Although thrombocytopenia is associated with many rheumatologic disorders, it is rare in IgG4-related MD. This novel study aims to report a rare case of IgG4-related MD complicated with severe autoimmune thrombocytopenia without any hematological malignancies and review all cases of lgG4-related disease associated with thrombocytopenia in the literature.

Keywords: Immunoglobulin G4-related disease; Mikulicz's disease; thrombocytopenia.
\end{abstract}

Immunoglobulin G4 (IgG4)-related Mikulicz's disease (MD) is an immune-mediated fibroinflammatory condition of unknown etiology characterized by the swelling of multiple exocrine glands including lacrimal, salivary, and parotid glands. ${ }^{1,2}$ Immune thrombocytopenia is common in many autoimmune diseases. However, IgG4-related $\mathrm{MD}$ is rarely associated with immune thrombocytopenia and its pathogenic mechanism remains largely unclear. To our knowledge, only one case has been reported to date in the literature. In that case, the patient developed severe thrombocytopenia after autologous peripheral blood stem cell transplantation (PBSCT) for multiple myeloma (MM). ${ }^{3}$ This novel study aims to report the case of a 48-year-old male patient suffering from MD with severe immune thrombocytopenia without hematological malignancies and review all reported cases of IgG4-related disease (IgG4-RD) with thrombocytopenia.

\section{CASE REPORT}

A 48-year-old male patient was admitted to our department with enlarged lacrimal and parotid glands associated with thrombocytopenia. $\mathrm{He}$ underwent resection for bilateral swelling of submandibular glands three years ago. The pathological examination revealed no tumor cells or focal lymphocytic infiltration. However, he repeatedly had enlarged lacrimal and parotid glands and dry mouth, without dry eye or arthralgia. He was then diagnosed with Sjögren syndrome (SS) and received anti-rheumatic treatment with hydroxychloroquine and Tripterygium wilfordii (a traditional Chinese medicine having definite effects on autoimmune and inflammatory diseases) for two years. However, the patient suffered from repeated recurrences of enlarged glands and presented with thrombocytopenia after two years. Physical examination revealed nontender bilateral swelling of lacrimal and

Received: June 10, 2018 Accepted: November 10, 2018 Published online: November 30, 2018

Correspondence: Fen Li, MD. Department of Rheumatology and Immunology, The Second Xiangya Hospital, Central South University, 410008 Changsha, China. Tel: 073185295255 e-mail: lifen0731@csu.edu.cn 


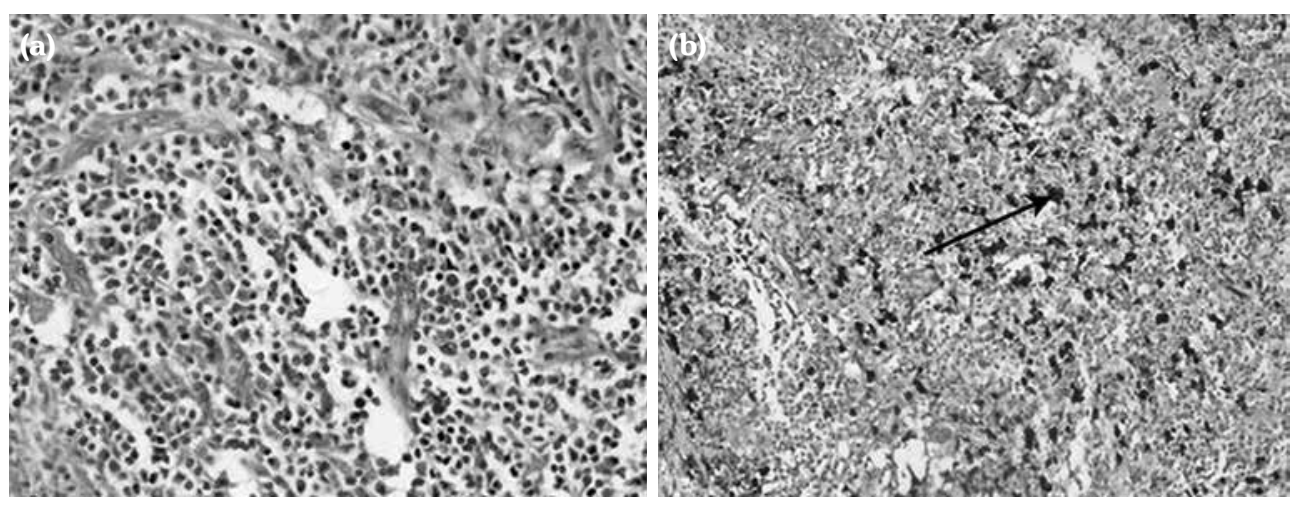

Figure 1. Histological findings of submandibular glands. (a) Massive infiltration of lymphocytes and plasma cells in submandibular gland tissue $(\mathrm{H}-\mathrm{E} \times 400)$; (b) Fibrosis with marked involvement of immunoglobulin G4+ plasma cells in submandibular gland tissue (indicated by an arrow, $\mathrm{H}-\mathrm{E} \times 400)$.

salivary glands (about $2 \times 1.2 \mathrm{~cm}^{2}$ ) and of multiple superficial lymph nodes. Laboratory studies showed severe thrombocytopenia (platelet [PLT] $6 \times 10^{9} / \mathrm{L}$, normal range $100-300 \times 10^{9} / \mathrm{L}$ ), serum IgG4 $4.52 \mathrm{~g} / \mathrm{L}$ (normal range 0.030-2.010 g/L), and negative angiotensin-converting enzyme and autoantibodies. The ophthalmological examination excluded dry eye. No focal lymphocytic infiltration was found in the biopsy of labial glands. Bone marrow cytology and biopsy results were normal. Subsequent positron emission tomography and computed tomography scan images showed abnormal glucose accumulation in several superficial lymph nodes, particularly left axillary lymph nodes (maximum standardized uptake value 11), suggesting a likelihood of lymphoma. The patient then underwent a biopsy of the swollen lymph node in the left armpit region. The pathological examination showed reactive hyperplasia of lymph nodes. Furthermore, the IgG4 immunohistochemical staining of the submandibular gland was performed. As shown in Figure 1, the pathological examination revealed IgG4 ${ }^{+}$cells $>10 /$ high-power field (HPF), and a

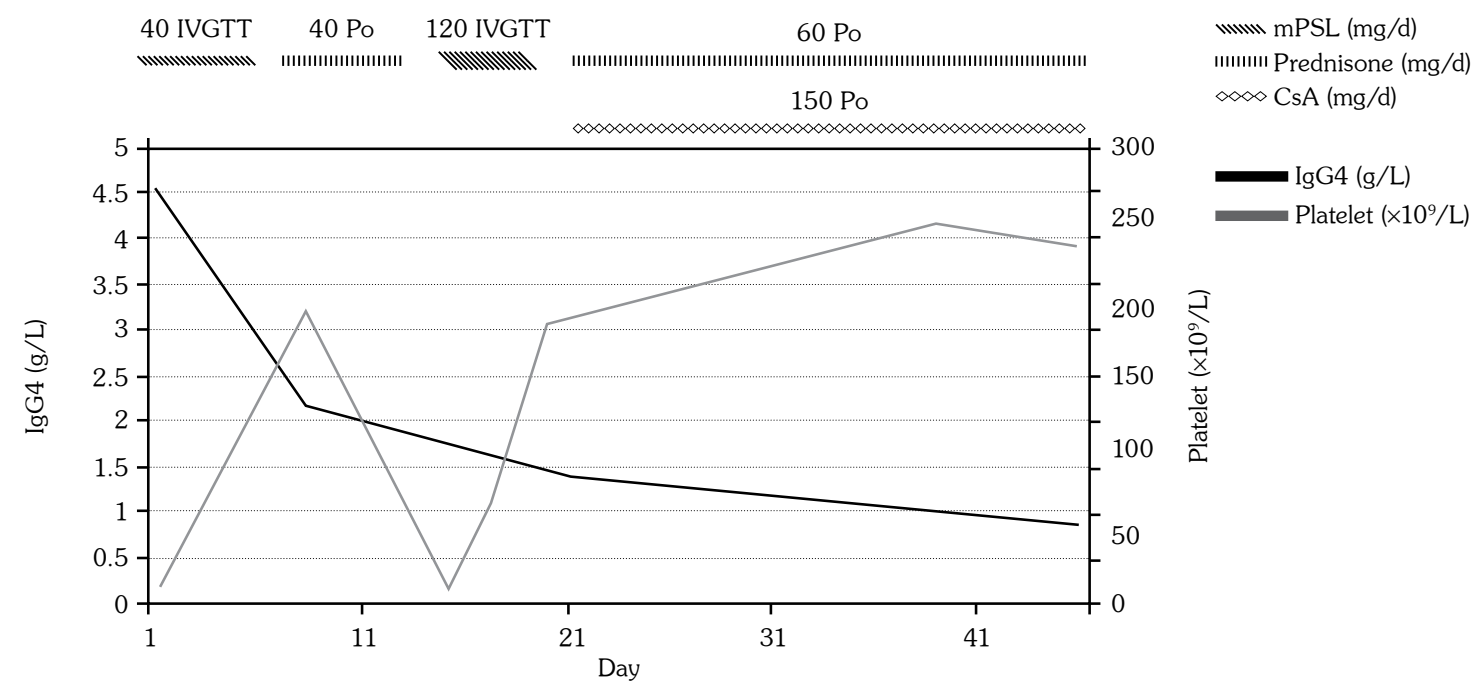

Figure 2. Patient's clinical course including changes in laboratory findings. Treatment with steroids and cyclosporine resulted in a gradual increase in platelet count and a decrease in immunoglobulin G4 level in peripheral blood.

IVGTT: Intravenous glucose tolerance test; Po: Per os; mPSL: Methylprednisolone; CsA: Cyclosporin A. 
proportion of $\mathrm{IgG}^{+} / \mathrm{IgG}^{+}$plasma cells $>50 \%$. The final diagnosis was IgG4-related MD with immune thrombocytopenia. The patient was given intravenous $40 \mathrm{mg}$ methylprednisolone for seven days. The swelling of glands reduced, and the PLT count recovered to the normal level $\left(193 \times 10^{9} / \mathrm{L}\right)$. The patient was treated with $40 \mathrm{mg}$ oral prednisone for seven days. Unexpectedly, he had repeated recurrences of the swelling of glands with severe thrombocytopenia $\left(10 \times 10^{9} / \mathrm{L}\right)$. Then, the patient received $120 \mathrm{mg}$ methylprednisolone for five days. The swelling of glands narrowed again, and the PLT count slowly increased $\left(56 \times 10^{9} / \mathrm{L}\right)$. The patient was given $60 \mathrm{mg}$ prednisone and $150 \mathrm{mg}$ cyclosporine. The swollen glands reduced to normal size, and the serum IgG4 level and PLT count returned to normal level in 1.5 months (Figure 2). A written informed consent was obtained from the patient according to the institutional guidelines.

\section{DISCUSSION}

Immunoglobulin G4-related MD, a fibrosisassociated inflammatory disease characterized by painless bilateral swelling of the lacrimal and salivary glands, is diagnosed based on the presence of a high serum concentration of $\mathrm{IgG} 4$ (>135 mg/dL) or histopathological findings of IgG4+ plasma cell infiltration in swollen lacrimal, parotid, or submandibular glands $\left(\mathrm{IgG} 4^{+}\right.$plasma cells $/ \mathrm{IgG}^{+}$plasma cells $>40 \%$, IgG4 ${ }^{+}$plasma cells $>10 / \mathrm{HPF}) .^{4,5} \mathrm{MD}$ is frequently misdiagnosed due to clinical features similar to those of SS. ${ }^{6,7}$ The biopsy of swollen glands and serum IgG4 testing helped in differential diagnosis between the two diseases. ${ }^{4,8}$ SS complicated with thrombocytopenia is common, while MD associated with thrombocytopenia is extremely rare. ${ }^{9}$ Only one case with MM has been reported to date in the literature. In that case, the patient developed severe thrombocytopenia after autologous PBSCT for MM. ${ }^{3}$ This study reported the first case of IgG4-related MD with immune thrombocytopenia without hematologic malignancies. In the present case, the diagnosis of IgG4-related MD was confirmed by the pathological examination of submandibular glands. Immunohistochemistry revealed $\mathrm{IgG}^{+}$ plasma cell infiltration in swollen submandibular glands (IgG4 ${ }^{+}$cells $>10 / \mathrm{HPF}$ and a proportion of $\mathrm{IgG}^{+} / \mathrm{IgG}^{+}$plasma cells $>50 \%$ ). Patient's response to steroid therapy was good. However, the PLT count of the patient decreased immediately after steroid reduction and returned to normal after treatment with a high dose of steroids and cyclosporine, suggesting that the steroid dose was recommended to be high and immunosuppressive agents could help in reducing the dose of steroids for the patient suffering from IgG4-related MD with thrombocytopenia. The pathogenic mechanism of thrombocytopenia in IgG4-related $\mathrm{MD}$ is largely unclear. In the present case, serum anti-SS type $\mathrm{A}$, anti-SS type $\mathrm{B}$, anti-deoxyribonucleic acid, and anti-nuclear antibodies were all negative. Considering that Helicobacter pylori (H. pylori) infection could contribute to IgG4-RD and thrombocytopenia, ${ }^{10}$ the $H$. pylori IgG was detected and 13C-urea breath test was performed. All these tests were negative. The study investigated whether thrombocytopenia was associated with increased IgG4. However, IgG4 was not detected in bone marrow tissue using immunohistochemistry. The PLT antibody in immune thrombocytopenia belonged mainly to the IgG1 and IgG3 subclasses of immunoglobulin. ${ }^{11,12}$ It was presumed that thrombocytopenia might be due to the presence of anti-PLT antibody of other subclasses of IgG such as IgG1 or IgG3. Unfortunately, this was just a speculation because anti-PLT antibodies or IgG subclass were not detected before treatment. All cases of IgG4-RD associated with thrombocytopenia in the literature were reviewed. IgG4-RD associated with thrombocytopenia was first described by Nakamura in a patient with autoimmune pancreatitis in 2003. ${ }^{13}$ Since then, only nine IgG4-RD cases complicated with thrombocytopenia have been reported (Table 1). All the cases responded well to steroid treatment. The mechanisms of thrombocytopenia is complicated in these reported cases. One reason for thrombocytopenia might be the presence of anti-PLT antibody. ${ }^{10,14}$ or IgG subclass (IgG1/3/4) of PLT antibody ${ }^{3,13,15-17}$ or autoantibody against a disintegrin and metalloproteinase with thrombospondin motifs $13^{18,19}$ Another reason is the $H$. pylori infection that could lead to a decrease in PLT count. ${ }^{10,16}$ In addition, impaired immunity due to autologous transplantation might also account for autoimmune thrombocytopenia. ${ }^{3}$ 
Table 1. Summary of cases of reported IgG4-RD with thrombocytopenia

\begin{tabular}{|c|c|c|c|c|}
\hline Author & IgG4-RD & Possible mechanism of thrombocytopenia & Treatment & Outcome \\
\hline Sakurai et al. ${ }^{3}$ & MD & $\begin{array}{l}\text { Impaired immunity due to autologous } \\
\text { transplantation; } \\
\text { Platelet-associated IgG was positive }\end{array}$ & $\begin{array}{l}\text { Immunoglobulin } \\
\text { mPSL }\end{array}$ & Improvement \\
\hline Takasumi et al. ${ }^{10}$ & IgG4-RD with PBC & $\begin{array}{l}\text { PBC related autoantibodies; } \\
\text { Platelet-associated IgG was positive; } \\
\text { HP infection }\end{array}$ & mPSL & Improvement \\
\hline Nakamura et al. ${ }^{13}$ & AIP & Platelet-associated IgG was positive & Prednisolone & Improvement \\
\hline Fukushima et al. ${ }^{15}$ & AIP & $\begin{array}{l}\text { Platelet-associated IgG was positive; } \\
\text { Antiplatelet antibody was positive }\end{array}$ & Prednisolone & Improvement \\
\hline Murase et al. ${ }^{16}$ & AIP & $\begin{array}{l}\text { PLT associated IgG was positive; } \\
\text { HP infection }\end{array}$ & Prednisolone & Improvement \\
\hline Morimoto et al. ${ }^{17}$ & $\begin{array}{l}\text { AIP } \\
\text { TIN } \\
\text { With } \\
\text { MPGN }\end{array}$ & $\begin{array}{l}\text { Platelet-associated IgG was positive; } \\
\text { The released CA II would form immune } \\
\text { complexes causing ITP }\end{array}$ & Prednisolone & Died \\
\hline Saeki et al. ${ }^{18}$ & $\begin{array}{l}\text { IgG4-RD } \\
\text { with TTP }\end{array}$ & IgG4 autoantibody against ADAMTS 13 & $\begin{array}{l}\text { Prednisolone; } \\
\text { Plasmapheresis }\end{array}$ & Improvement \\
\hline Foguem et al. ${ }^{19}$ & AIP with TTP & $\begin{array}{l}\text { Large vWF multimers in TTP; } \\
\text { Autoantibodies against ADAMTS 13's }\end{array}$ & $\begin{array}{l}\text { mPSL } \\
\text { Plasmapheresis } \\
\text { Vincristin Rituximab }\end{array}$ & Improvement \\
\hline Shimazuet al. ${ }^{14}$ & $\begin{array}{l}\text { IgG4-RD } \\
\text { with AIN }\end{array}$ & $\begin{array}{l}\text { Autoantibodies against platelet surface } \\
\text { proteins }\end{array}$ & Prednisolone & Improvement \\
\hline
\end{tabular}

In summary, this novel study described a rare case of IgG4-related MD complicated with autoimmune thrombocytopenia without any hematologic malignancies. Although IgG4-related MD had a favorable response to steroid therapy, the steroid dose was recommended to be high and immunosuppressive agents helped in reducing the dose of steroids for the patient suffering from IgG4-related MD with thrombocytopenia.

\section{Declaration of conflicting interests}

The authors declared no conflicts of interest with respect to the authorship and/or publication of this article.

\section{Funding}

This work was supported by grants from the National Natural Science Foundation of China Youth Fund (No. 81302567).

\section{REFERENCES}

1. Kamisawa T, Zen Y, Pillai S, Stone JH. IgG4-related disease. Lancet 2015;385:1460-71.
2. Himi T, Takano K, Yamamoto M, Naishiro Y, Takahashi $\mathrm{H}$. A novel concept of Mikulicz's disease as IgG4related disease. Auris Nasus Larynx 2012;39:9-17.

3. Sakurai C, Ohashi K, Sakaguchi K, Hishima T, Kamata N, Akiyama H, et al. Mikulicz's disease with severe thrombocytopenia following autologous stem cell transplantation in a multiple myeloma patient. Int J Hematol 2009;90:532-6.

4. Takahashi H, Yamamoto M, Tabeya T, Suzuki C, Naishiro Y, Shinomura Y, et al. The immunobiology and clinical characteristics of IgG4 related diseases. J Autoimmun 2012;39:93-6.

5. Stone JH, Khosroshahi A, Deshpande V, Chan JK, Heathcote JG, Aalberse R, et al. Recommendations for the nomenclature of IgG4-related disease and its individual organ system manifestations. Arthritis Rheum 2012;64:3061-7.

6. Yao Q, Wu G, Hoschar A. IgG4-related Mikulicz's disease is a multiorgan lymphoproliferative disease distinct from Sjögren's syndrome: a Caucasian patient and literature review. Clin Exp Rheumatol 2013;31:289-94.

7. Fragoulis GE, Zampeli E, Moutsopoulos HM. IgG4related sialadenitis and Sjögren's syndrome. Oral Dis 2017;23:152-6. 
8. Avincsal MO, Zen Y. The Histopathology of IgG4Related Disease. Curr Top Microbiol Immunol 2017;401:45-60.

9. Choung BS, Yoo WH. Successful treatment with intravenous immunoglobulin of severe thrombocytopenia complicated in primary Sjögren's syndrome. Rheumatol Int 2012;32:1353-5.

10. Takasumi M, Miyata M, Kuroda M, Terashima K, Abe K, Takahashi A, et al. Overlap of IgG4-related Disease and Primary Biliary Cirrhosis Complicated with Autoimmune Thrombocytopenia. Intern Med 2016;55:1387-92.

11. Huh HJ, Park CJ, Kim SW, Han SH, Jang S, Chi HS. Flow cytometric detection of plateletassociated immunoglobulin in patients with immune thrombocytopenic purpura and nonimmune thrombocytopenia. Ann Clin Lab Sci 2009;39:283-8.

12. Teeling JL, Jansen-Hendriks T, Kuijpers TW, de Haas $\mathrm{M}$, van de Winkel JG, Hack CE, et al. Therapeutic efficacy of intravenous immunoglobulin preparations depends on the immunoglobulin $G$ dimers: studies in experimental immune thrombocytopenia. Blood 2001;98:1095-9.

13. Nakamura A, Funatomi H, Katagiri A, Katayose $\mathrm{K}$, Kitamura $\mathrm{K}$, Seki $\mathrm{T}$, et al. A case of autoimmune pancreatitis complicated with immune thrombocytopenia during maintenance therapy with prednisolone. Dig Dis Sci 2003;48:1968-71.

14. Shimazu Y, Uchiyama T, Mizumoto C, Takeoka T,
Tsuji M, Tomo K, et al. Concurrent Autoimmune Neutropenia and Idiopathic Thrombocytopenic Purpura Associated with IgG4-related Diease. Intern Med. 2018;57:1911-6.

15. Fukushima H, Katou E, Nagayama K, Shirachi A, Sata M. A case of autoimmune pancreatitis complicated with immune thrombocytopenia. Nihon Shokakibyo Gakkai Zasshi 2006 ;103:661-6.

16. Murase K, Matsunaga T, Hayashi T, Ishiwatari $H$, Araki N, Iyama $\mathrm{S}$, et al. Successful treatment of autoimmune pancreatitis complicated with autoimmune thrombocytopenia and interstitial pneumonia by prednisolone. Intern Med 2008;47:1033-8.

17. Morimoto J, Hasegawa Y, Fukushima H, Uesugi $\mathrm{N}$, Hisano S, Saito T, et al. Membranoproliferative glomerulonephritis-like glomerular disease and concurrent tubulointerstitial nephritis complicating IgG4-related autoimmune pancreatitis. Intern Med 2009;48:157-62.

18. Saeki $\mathrm{T}$, Ito $\mathrm{T}$, Youkou $\mathrm{A}$, Ishiguro $\mathrm{H}$, Sato $\mathrm{N}$, Yamazaki $\mathrm{H}$, et al. Thrombotic thrombocytopenic purpura in IgG4-related disease with severe deficiency of ADAMTS-13 activity and IgG4 autoantibody against ADAMTS-13. Arthritis Care Res (Hoboken) 2011;63:1209-12.

19. Foguem C, Boruchowicz A, Cuingnet $\mathrm{P}$, Kyndt X. Thrombotic thrombocytopenic purpura (TTP) leading to pseudotumour's autoimmune pancreatitis (AIP): a case report. Pancreatology 2013;13:90-4. 